\title{
Descargas complexas repetitivas em um equino com miopatia distrófica
}

Luiza Stachewski Zakia ${ }^{[a]}$, Mariana Isa Poci Palumbo ${ }^{[b]}$, Raffaella BC Teixeira ${ }^{[c]}$, Luiz Antonio de Lima Resende ${ }^{[d]}$, Mauro Pereira Soares ${ }^{[]]}$, Rogerio M. Amorim ${ }^{[a]}$, Jose Paes de Oliveira-Filho ${ }^{[a]}$, Alexandre Secorun Borges ${ }^{[a]^{\circ}}$

\footnotetext{
[a] Faculdade de Medicina Veterinária e Zootecnia, Universidade Estadual Paulista (UNESP), Botucatu, SP, Brasil

[b] Universidade Federal de Mato Grosso do Sul (UFMS), Campo Grande, MS, Brasil

[c] University of Minnesota (UMN), Minneapolis, MM, Estados Unidos

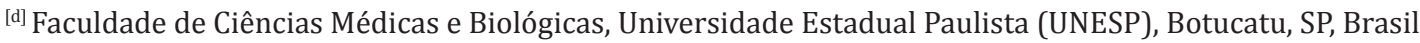

[e] Universidade Federal de Pelotas (UFPel), Pelotas, RS, Brasil
}

*Autor correspondente

e-mail: asborges@fmvz.unesp.br

\section{Resumo}

As miopatias em equinos podem ser de origem genética, metabólica, tóxica ou inflamatória. 0 reconhecimento da clínica destas enfermidades e associação aos achados histológicos e eletromiográficos são essenciais. As principais miopatias que manifestam miotonia são a paralisia periódica hipercalêmica (HYPP), miotonia distrófica e miotonia congênita. 0 presente relato tem como objetivo descrever os seus achados histológicos e eletromiográficos em equino macho, mestiço Quarto de Milha e Puro Sangue Inglês, de 19 meses de idade, encaminhado à Clínica Médica de Grandes Animais da Faculdade de Medicina Veterinária e Zootecnia da Universidade Estadual Paulista, campus de Botucatu. Ao exame físico, o animal possuía parâmetros vitais dentro da normalidade, rigidez muscular bilateral, hipertrofia dos músculos da garupa e miocimia paravertebrais e glúteo, teste de dimpling positivo e andar rígido. 0 animal foi testado geneticamente e foi negativo para HYPP. 0 exame de hemograma e bioquímica sérica, incluindo funções renal e hepática, não revelaram alterações. Apenas os níveis de creatinina quinase estavam aumentados (396 UI/L). 0 resultado da hemogasometria venosa, triiodotironina (T3) e tiroxina (T4), assim como da glicose sanguínea, estavam dentro da normalidade. Descargas repetitivas complexas que não variavam em frequência ou amplitude foram encontradas na eletromiografia. Distrofia muscular com núcleos centrais e variação no parâmetro das fibras em tamanho e também proliferação de tecido conectivo com degeneração miofibrilar com fibras necróticas foram observadas na histologia do músculo glúteo médio. Miofibras com tumefação mitocondrial e lise das cristas, acúmulo de fluído entre as miofibrilas e desorganização dos sarcômeros foram observados 
na microscopia eletrônica. Com isso, é possível concluir que o presente caso apresenta miopatia distrófica e que o diagnóstico destas enfermidades é imprescindível para o estabelecimento do prognóstico correto do animal.

Palavras-chave: Miopatia. Distrofia. Eletromiografia. 